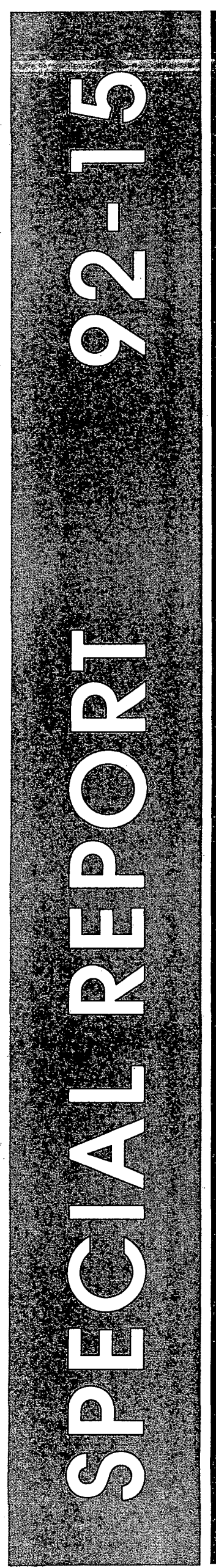

\title{
Digging Frozen Ground with a Ripper Bucket
}

Paul V. Sellmann and Bruce E. Brockett

June 1992

U.S. ARMY COLD REGIONS RESEARCH AND. ENGINEERING LABORATORY

ATTN: Library

T2 Lyme Road

Hanover, NH 03755 
For conversion of SI metric units to U.S./British customary units of measurement consult ASTM Standard E380, Metric Practice Guide, published by the American Society for Testing and Materials, 1916 Race St., Philadelphia, Pa. 19103. 


\section{Special Report 92-15}

Cold Regions Research \& Engineering Laboratory

\section{Digging Frozen Ground with a Ripper Bucket}

Paul V. Sellmann and Bruce E. Brockett

June 1992 


\section{PREFACE}

This report was prepared by Paul V. Sellmann, Geologist, Civil and Geotechnical Engineering Research Branch, Experimental Engineering Division, and Bruce E. Brockett, Physical Science Technician, Geological Sciences Branch, Research Division, U.S. Army Cold Regions Research and Engineering Laboratory. Funding for this project was provided by DA Project 4A762784AT42, Cold Regions Engineering Technology; Task CS; Work Unit 029, Combat Engineering in Winter.

The authors are grateful to Herbert Ueda and Donald Garfield, both of CRREL, for reviewing this report and for making a number of useful comments and suggestions.

The contents of this report are not to be used for advertising or promotional purposes and are not intended to provide any positive or negative impact upon commercial products. Citation of brand names does not constitute an official endorsement or approval of the use of such commercial products. 


\title{
Digging Frozen Ground with a Ripper Bucket
}

\author{
PAUL V. SELLMANN AND BRUCE E. BROCKETT
}

\section{INTRODUCTION}

This report was prepared as part of an assessment to see if a ripper bucket will substantially improve the digging performance of small backhoes and excavators when hard digging is encountered. This is of interest to some Army engineer units that rely only on light-weight equipment for excavating hard and frozen ground. An additional incentive is that light-weight mini-excavators are becoming more available and are easily transported.

The Army Small Emplacement Excavator (SEE), a rubber-tired machine with a rear-mounted backhoe, and a commercial mini-excavator were used for these observations. Thestandard backhoebucket on the mini-excavator and the SEE bucket, with a removable single tooth ripper, were replaced with a heavy-duty ripper bucket that was designed and constructed by Wain-Roy, Inc., for digging weak rock, hard ground and frozen soil. The ripper bucket has conventional lip cutters and a set of staggered teeth permanently mounted on the back side of the bucket that cut and rip as it is rotated through the work. Two types of teeth were obtained for our observations-pointed and wedge.

Seasonally frozen soil was excavated at two sites, one containing scattered stones and another with rocks, in northern $\mathrm{New}$ England and northern $\mathrm{New}$ York State. Other observations in Alaska were conducted in permafrost terrain, where soils ranged from ice-rich silty sand to well-bonded, coarsegrained material. Observations included digging characteristics with different tooth configurations, excavation rates and notes regarding digging techniques.

\section{EQUIPMENT}

A mini-excavator (Bobcat 100) and an Army Small Emplacement Excavator (SEE) were used for the digging. The mini-excavator had an operating weight of $6945 \mathrm{lb}(3150 \mathrm{~kg})$ and was selected be, cause of its weight and local availability (Fig. 1). The SEE is a highly mobile, rubber-tired tractor with a front-mounted loader and rear-mounted Case backhoe, as illustrated in Figure 2. It is intended to enhance the excavating capability of military engineering units and explosive ordnance disposal units, and to provide tactical mobility over rough terrain as well as over highways.

Maximum digging force at the bucket for a range of smaller mini-excavators was plotted against operating weight (Fig. 3), providing a means of comparing these machines and an indication of their digging capability: The value of $5070 \mathrm{lbf}(22.6$ $\mathrm{kN})$ at the upper right of the plot is for the Bobcat 100 . This value is apparently the maximum bucket force generated by the hydraulic cylinder providing bucket rotation or roll. Specifications for a large range of excavators can be found in Highway and Heavy Construction (Smith 1987, Popp 1991).

The standard buckets on the Bobcat 100 and SEE were replaced with ripper buckets that have lip teeth and five staggered teeth on their backs (Fig. 4). The 12-in. (30-cm) wide bucket has three lip teeth and the 16-in. $(40-\mathrm{cm})$ has five. In these two sizes the combination of lip and ripper teeth cut almost the entire surface being advanced. The teeth are arranged on a constant radius (Fig. 4), and as the bucket is rotated through the earth it acts much like a segment of a bucket wheel excavator. A recom- 


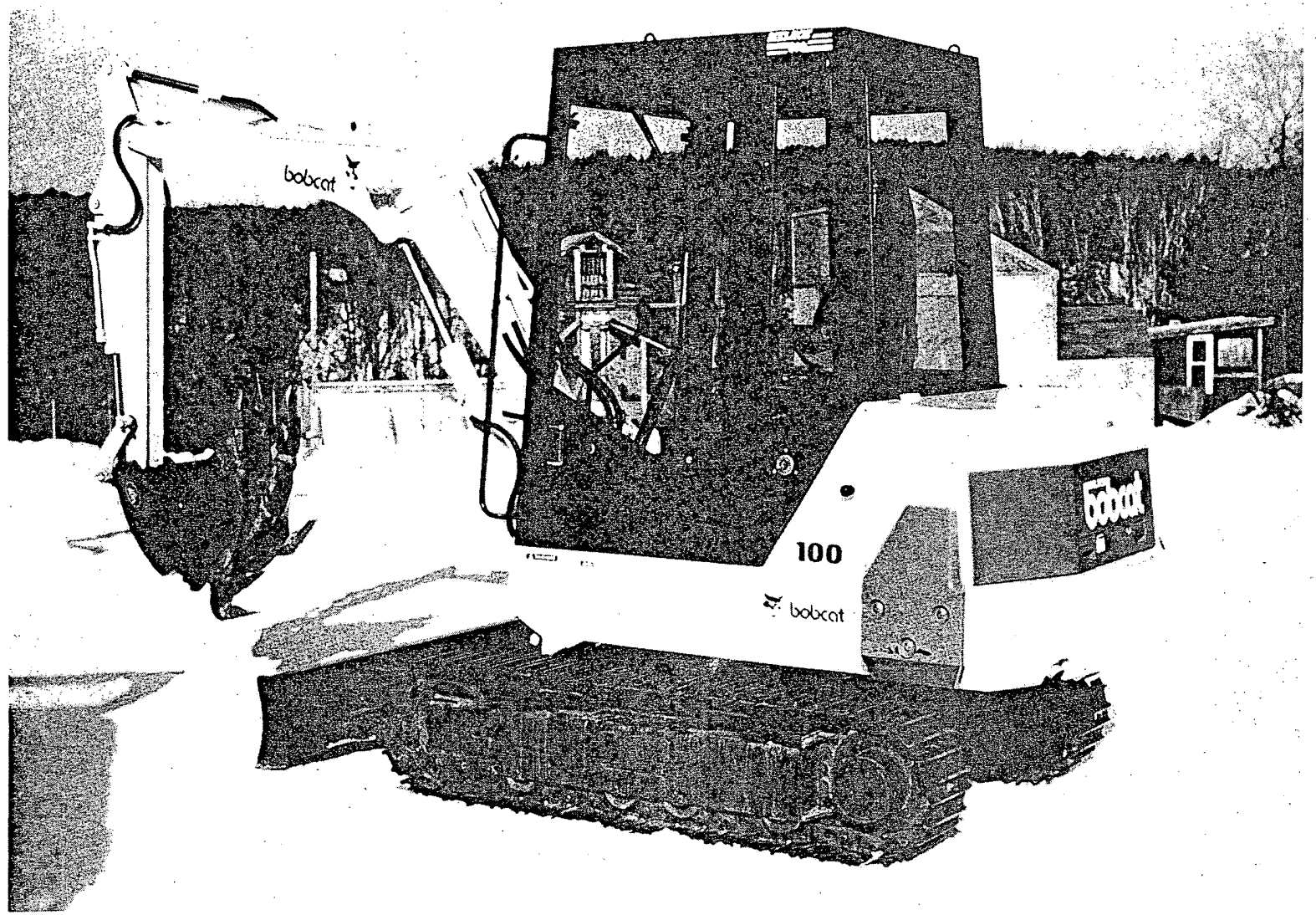

Figure 1. Bobcat 100 hydraulic excavator used for some of the digging observations (track length 81 in. [2065 mm]).

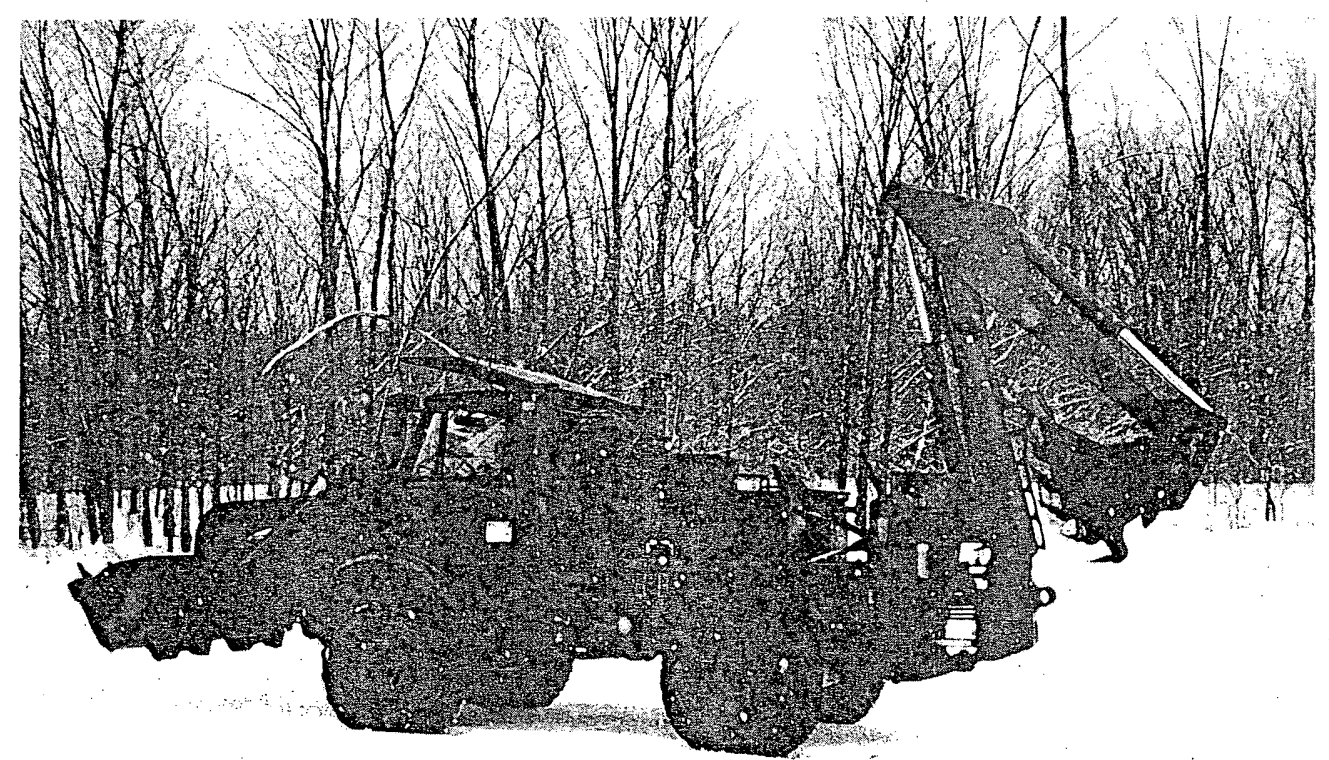

Figure 2. Small Emplacement Excavator (SEE) manufactured by Freightliner Corporation. A ripper bucket is shown on the backhoe. 


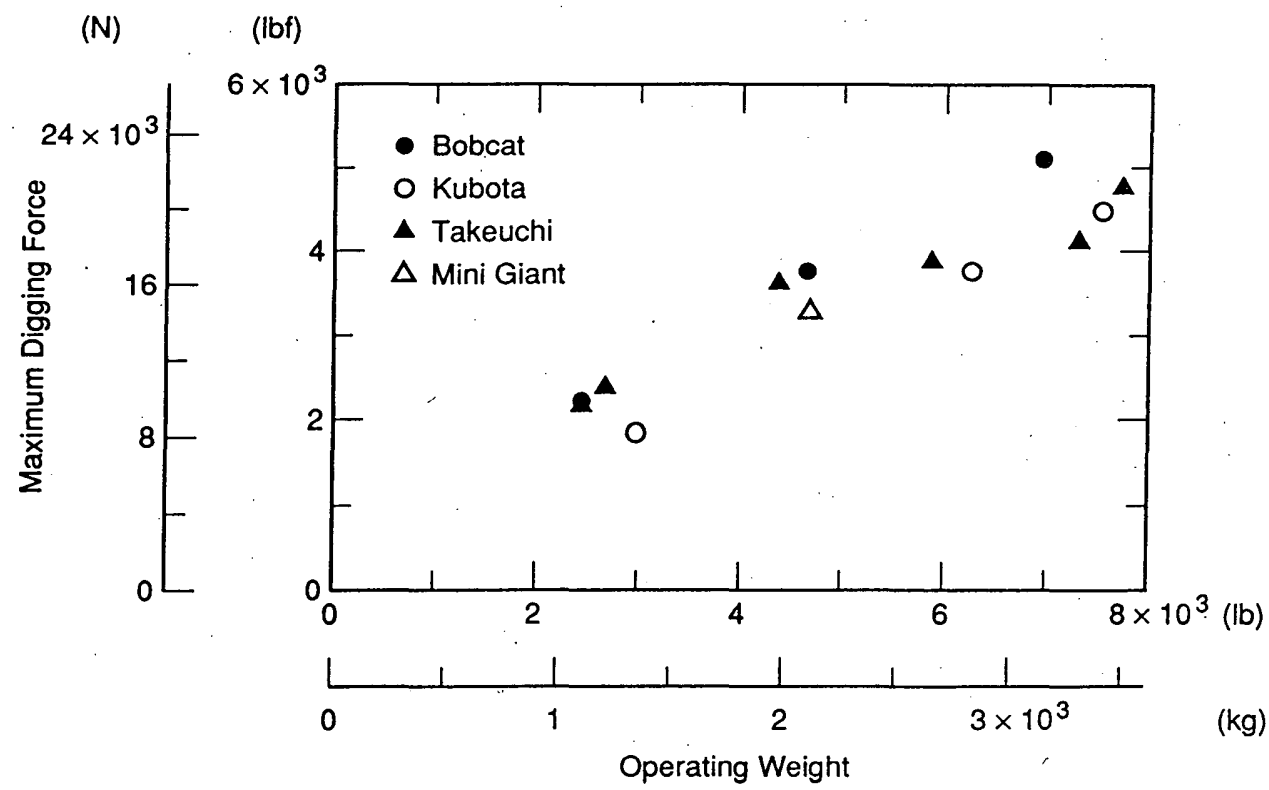

Figure 3. Maximum digging force for a number of smaller mini-excavators that have operating weights of less than $8000 \mathrm{lb}(3628 \mathrm{~kg}$ ) (data from product literature).

Figure 4. Views of the Wain-Roy ripper bucket showing general configuration of teeth on the bucket (after Wain-Roy, Inc., product literature).
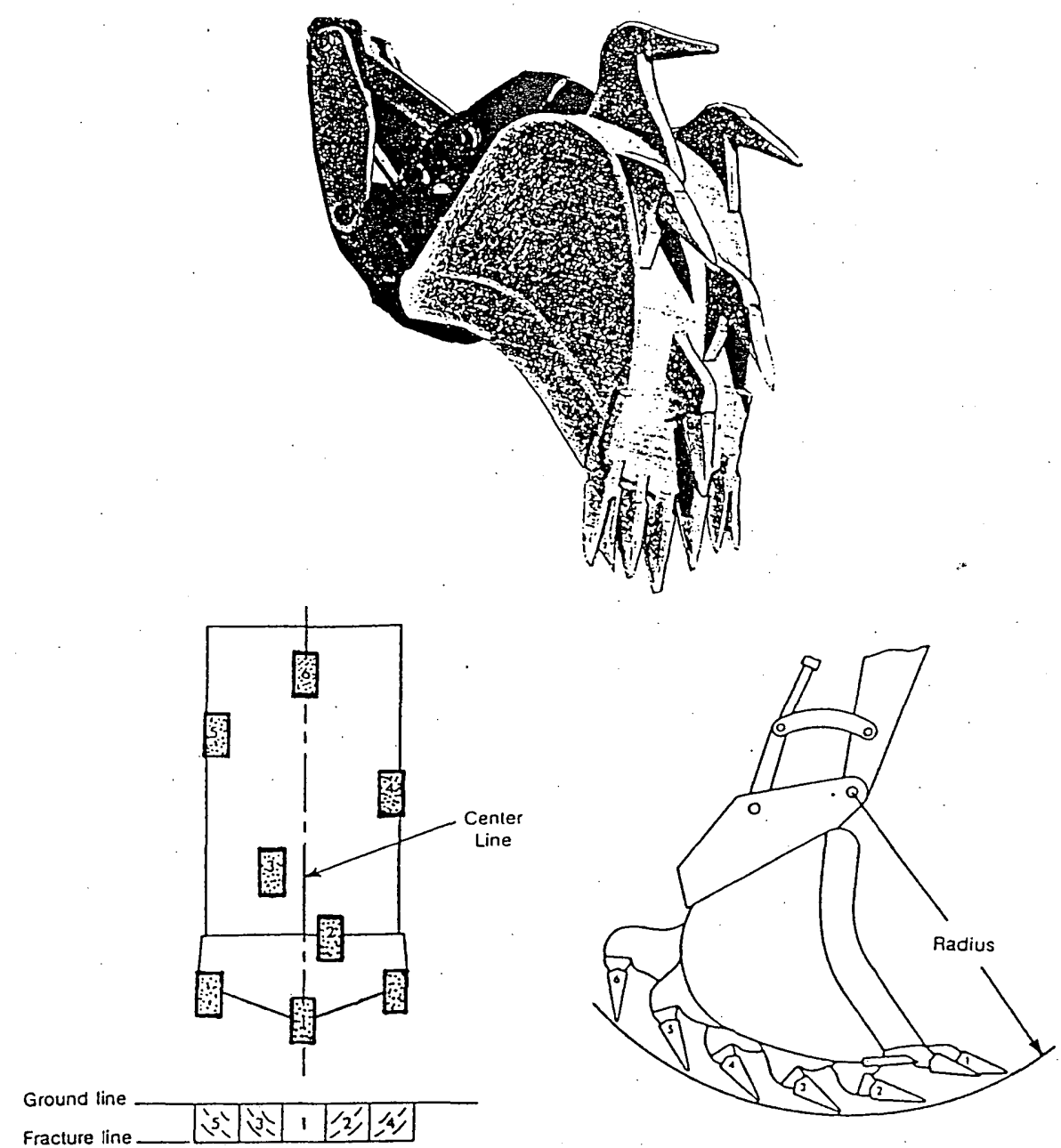

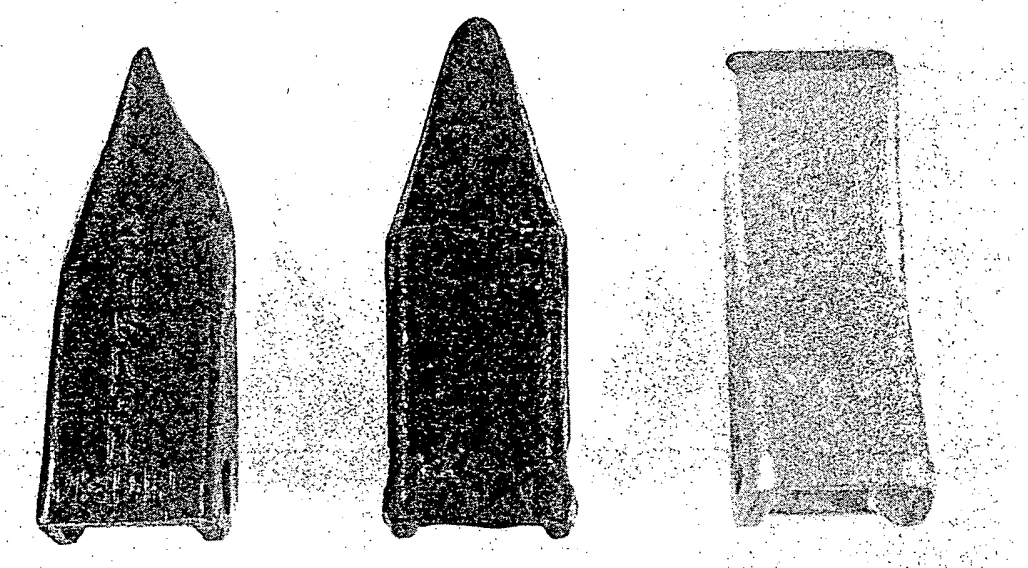

Figure 5. Three types of teeth obtained with the bucket: a pointed Hensely tooth at the left, a more rounded one in the center, and the sharpened wedge on the right.

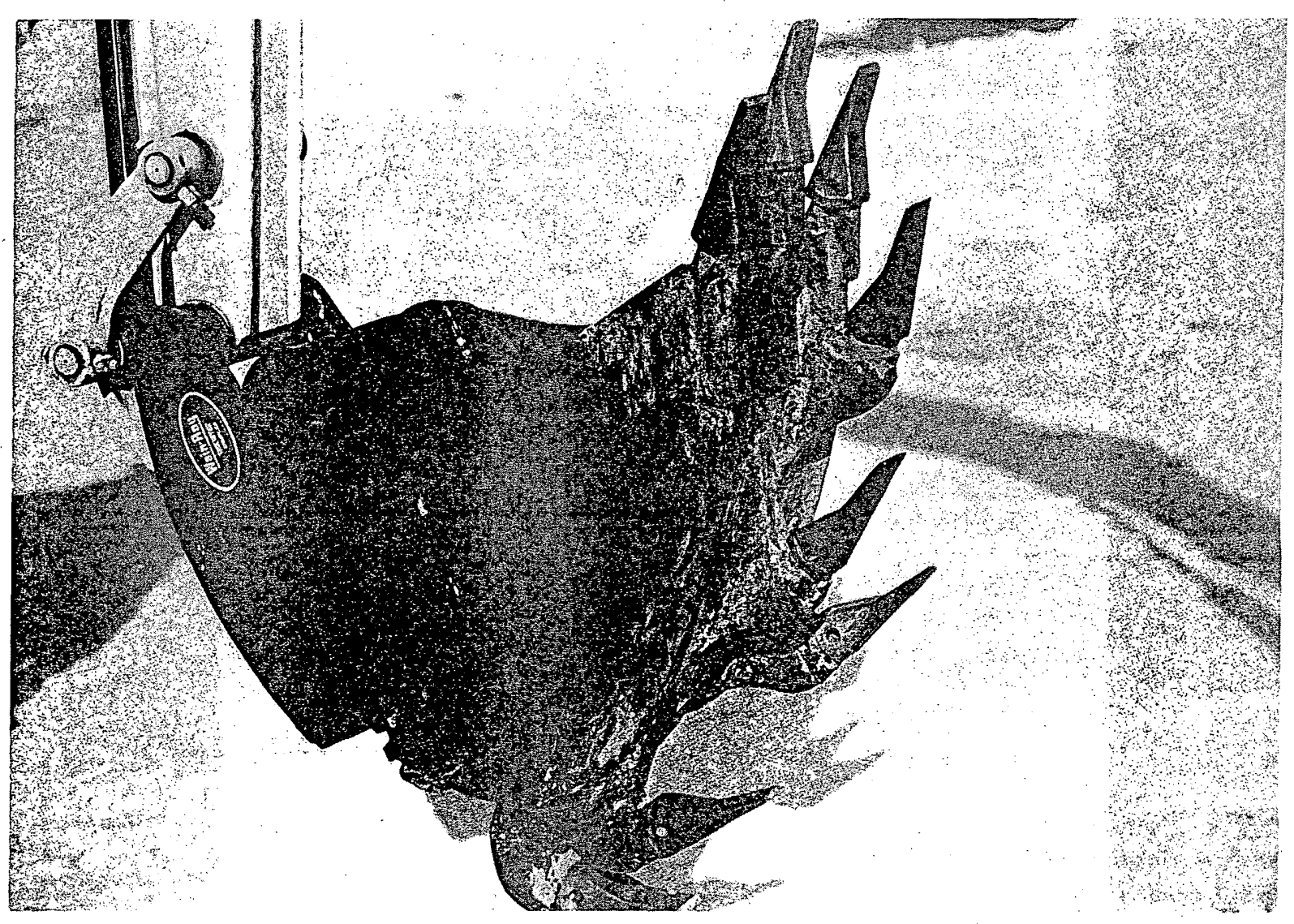

Figure 6. A 12-in. (30-cm) ripper bucket mounted on the mini-excavator. Sharpened wedge teeth attached in this configuration provided the best performance with this small machine. 
mended digging procedure is to operate with the outer element of the boom near vertical to provide downward pressure. The bucket is rolled fully back and loaded vertically, then forward rotation sequentially moves the teeth through the ground, taking advantage of the high forces generated during bucket roll. This routine is repeated until enough material is produced to justify a cleanup cycle.

Three types of teeth were considered when the buckets were acquired (Fig. 5). The simple wedge and the pointed tipped Hensely teeth were both used for our digging observations. The one in the center of Figure 5 was not used because of its bluntness. The wedge tooth was sharpened and the Hensely was used as provided. Sharpening is not normally done to teeth used on large diggers and excavators, but was done in this case to provide the small machines with as much advantage as possible, since the wedge was particularly blunt. The two teeth used were asymmetrical in side view, which allowed them to be installed inverted for more than one cutting geometry. Figure 6 shows the flat wedge teeth on a 12 -in. $(30-\mathrm{cm})$ bucket, in a configuration that provided the best performance for the mini-excavator. The lip teeth did not have the same orientation as the teeth on the back of the bucket. This was done to lower the cutting edges of the lip teeth closer to the arch cut by those on the back of the bucket. Additional comments regarding tooth configuration are included in following sections.

\section{GENERAL CHARACTERISTICS OF FROZEN SOILS}

Significant excavation problems are caused by even thin layers of frozen ground, since soil and rock undergo significant increases in strength with freezing, as shown by the data plotted in Figure 7. Soil strengths increase dramatically with freezing, one to two orders of magnitude, because of the bonding provided by the ice. The strength of frozen soils continues to increase with cooling at temperatures normally encountered under natural conditions. Frozen soil strengths can approach those of unfrozen chemically bonded materials, such as weak rock and concrete.

For excavation, it is convenient to classify frozen soils broadly based on grain size. The fine-grained soils include various mixtures of silt, clay, organic material and ice. Of the frozen soils, these are usually most easily ripped and cut. Coarse-grained frozen soils consist primarily of sand and gravel, with aggregates ranging from small pebbles to large cobbles. The high strength, often large particle size and abrasive nature of this material make it

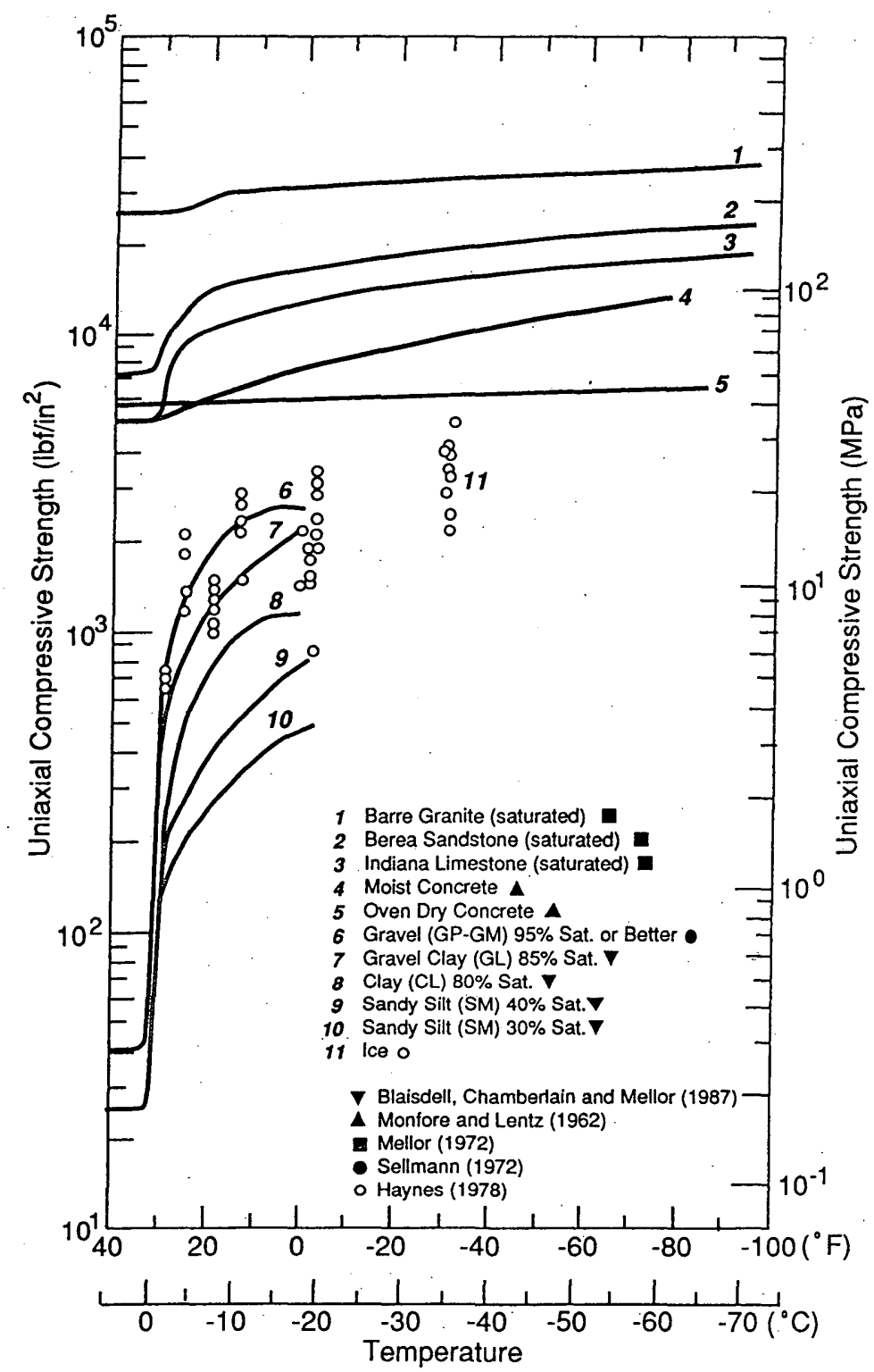

Figure 7. Effect of freezing and subsequent cooling on the unconfined compressive strength of concrete and earth materials: soil, rock and ice (from Sellmann 1989). 
difficult to impossible for a small machine to excavate, and under best conditions will cause significant tool wear. Machines with large teeth compared to aggregate size, and that can generate high tool forces, have the best chance of working this material.

Some sedimentary rocks and frozen, coarsegrained soils can be brittle and friable, and when they are attacked by widely spaced, claw-like teeth, the material between the teeth tends to break and crumble. By contrast, when ductile, frozen, finegrained soils are attacked by similar arrays of widely spaced teeth, they cut furrows but do not necessarily break out the material between them. This material can rub on noncutting surfaces and slow excavation. Thus, in frozen materials, to ensure proper performance under all ground conditions and temperatures, the entire area being removed should be worked or cut.

\section{STUDY SITES}

Observations were made at three locations. The mini-excavator was used at the CRREL facility in
Hanover, New Hampshire. The SEE was used at Fort Drum, New York, and at Fort Wainwright, Alaska, on machines belonging to the 41st Engineer Battalion and the 6th Engineers, respectively.

A significant contrast in digging conditions existed among the sites. Excavation in Hanover was done in a silty soil and in a sandy soil, both having scattered stones. The depth of seasonal frost varied. from 27 to $30 \mathrm{in}$. (70-75 cm). An effort was made to increase the strength of the sandy soil by soaking it as the ground was freezing. Examination of the trenches indicated that these soils were well bonded by ice throughout the seasonal frost layer.

At the Fort Drum site, the frost thickness varied from 9 to 16 in. ( 23 to $33 \mathrm{~cm}$ ). The frozen surface layer consisted of sandy clay, was well bonded by ice and contained some small to moderate sized stones. In Alaska the frost layer at the excavation sites was many feet thick, and the surface consisted of a gravelly silt layer approximately $1.5 \mathrm{ft}(45 \mathrm{~cm})$ thick over a sandy silt. This material was extremely well-bonded by ice and in some locations the gravelly section had the appearance and texture of concrete.

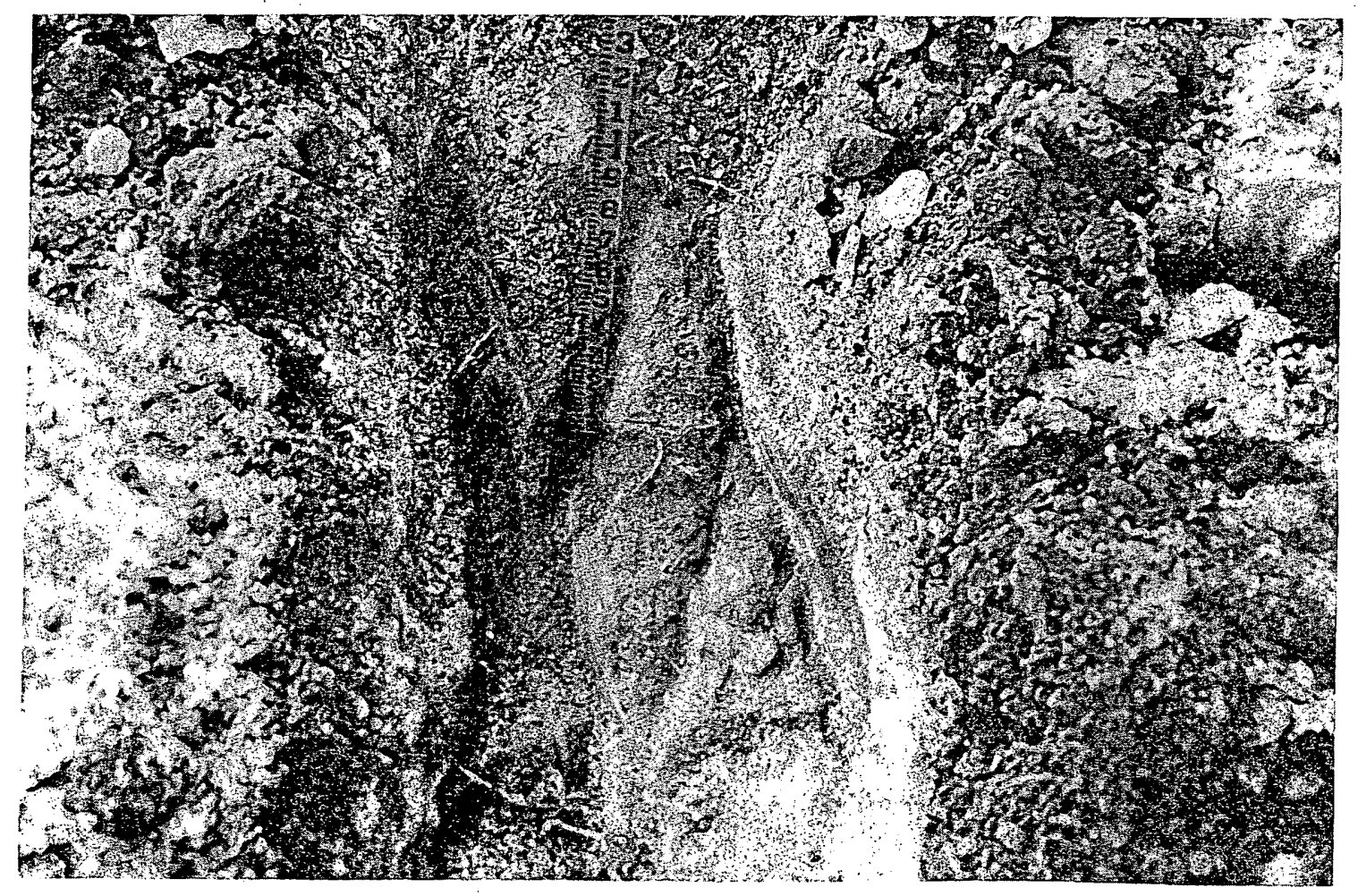

Figure 8. Uneven walls and floor produced with the pointed teeth. 


\section{RESULTS}

At all sites excavation rates were determined from timed intervals of digging. The average depth of cut per bucket roll was also determined to provide information on tooth performance. Most of the excavation data reported were obtained with teeth that were sharp, except in cases when performance between used and sharp teeth was contrasted. In a case where it appeared that excavation might be possible with the conventional bucket, a comparison was made with the ripper bucket.

\section{Mini-excavator}

The average depth of cut of the teeth on the 12-in. $(30-\mathrm{cm})$ ripper bucket used on the mini-excavator was determined based on 13 runs in frozen silt and 11 runs in the frozen sand. Each run consisted of a series of 4 to 14 bucket rolls. Sharpened, straightedged wedge teeth were used on both the lip and the shanks on the back of the bucket. The average depth of penetration in the silt was $0.5 \mathrm{in} .(1.25 \mathrm{~cm})$ per bucket roll, with values ranging from 0.1 to 1.1 in. $(0.25-2.80 \mathrm{~cm})$. Average penetration per roll in the sand was $0.3 \mathrm{in} .(0.76 \mathrm{~cm})$, with values ranging from 0.1 to $0.6 \mathrm{in}$. $(0.25-1.52 \mathrm{~cm})$.

Excavation rates were determined during timed runs. The runs were usually 10 minutes long and provided fairly consistent values that ranged from 19 to $36 \mathrm{ft}^{3} / \mathrm{hr}\left(0.6\right.$ to $\left.1.1 \mathrm{~m}^{3} / \mathrm{hr}\right)$. The average for all the runs was $26 \mathrm{ft}^{3} / \mathrm{hr}\left(0.78 \mathrm{~m}^{3} / \mathrm{hr}\right)$.

All of the data for the mini-excavator were obtained with the sharpened, wedge-shaped teeth. Attempts to use the pointed cutters were not as productive. The wedge teeth cut a wider path, were more aggressive, ran more evenly through the work and produced larger, more uniform-sized cuttings. Lateral stability of the bucket was also greatest with the wedge teeth, producing an even hole with parallel cuts, compared to the random pattern seen in Figure 8 that was created when pointed teeth were used. This light-weight excavator was not rigid or stiff enough to control or limit lateral bucket action. The pointed cutters wandered, and adjacent teeth intended to cut a separate path often moved over to occupy a previously cut groove. This deepened individual grooves and increased tooth contact area, slowing penetration, since increased contact reduces available thrust for tooth penetration. The cutting edge on the pointed teeth has about twice the contact area of the wedge teeth for the same width of cut. The pointed teeth would be better suited for use on a larger machine since they may require less maintenance and pro- duce higher point loading for fracture of high strength material.

\section{SEE excavator}

At Fort Drum we compared the performance of the standard 24-in. $(60-\mathrm{cm})$ bucket on the SEE and a 16-in. $(40-\mathrm{cm})$ wide ripper bucket. The machine with the standard bucket was unable to directly penetrate the seasonally frozen ground. The lip teeth slid across the ground, making only shallow indentations and frequently caught and pulled the tractor toward the bucket, requiring repositioning of the machine before additional digging. After continuing to work the the same $2-\times 3-\mathrm{ft}(60-\times 90-$ $\mathrm{cm})$ area, the operator eventually worked the lip teeth through a thin area (approximately 9 in. [23 $\mathrm{cm}$ ] of frost) in the frozen ground. In contrast immediate penetration was achieved with the ripper bucket. In a 10- $\times 7-\mathrm{ft}(3-\times 2-\mathrm{m})$ area, the 9- to 16in. (23- to $40-\mathrm{cm}$ ) thick frost layer was completely broken and partially removed in less than 5 minutes. This was accomplished by an Army operator who had about 10 minutes of experience using the ripper bucket. This area could then have been excavated with the standard bucket while the machine with the ripper bucket prepared another area.

At Fort Wainwright, Alaska, three Army operators used a Ripper Bucket fitted on a SEE. They made no attempt to use a standard bucket, since their experience indicated it would not dig the frozen ground. When digging was required, they relied on slow progress with a jackhammer.

Digging rates with the ripper bucket in Alaska varied, depending on the operator; however, all operators rapidly developed effective digging techniques. The excavation rates (based on 10-minute runs) with the 12-in. (30-cm) bucket ranged from 2.5 to $9.5 \mathrm{yd}^{3} / \mathrm{hr}\left(1.9\right.$ to $\left.7.3 \mathrm{~m}^{3} / \mathrm{hr}\right)$, depending on the operator, the sharpness of the bucket teeth and technique used to prevent movement of the machine during digging. The large fragments produced during digging are shown in Figure 9; this photo was taken as the ripper bucket was used to start an excavation. The material excavated at this site was very strong and abrasive.

The volumetric excavation data obtained with the mini-excavator were used to determine an approximate value of the overall specific energy for frozen ground excavation with the $12-\mathrm{in} .(30-\mathrm{cm})$ ripper bucket. We arrived at a specific energy of $11,000 \mathrm{lbf} /$ in. $^{2}\left(76 \mathrm{MN} / \mathrm{m}^{2}\right)$ by assuming that approximately three-quarters of the machine power could be mobilized by the hydraulic system. This 


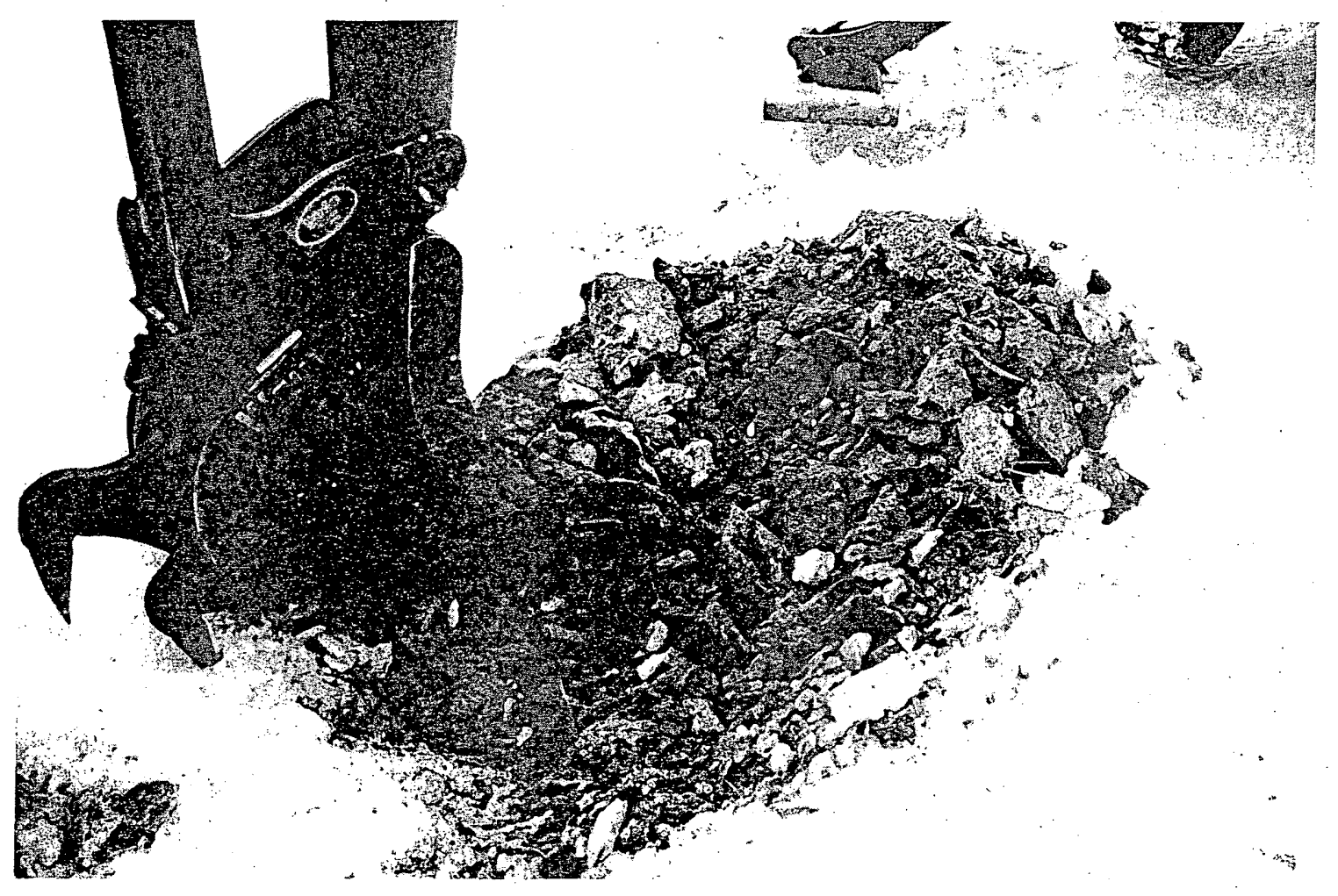

Figure 9. Hard, frozen ground ripped into large fragments during observations at Fort Wainwright, Alaska.

value for a cyclic process is high compared to other equipment used to continuously penetrate frozen ground. However, it compares well with a value of $13,000 \mathrm{lbf} / \mathrm{in}^{2}{ }^{2}\left(90 \mathrm{MN} / \mathrm{m}^{2}\right)$ obtained for a large auger drill that also excavated and removed frozen material as separate operations (Mellor and Sellmann 1975).

Digging performance decreased when the machine was free to move during aggressive digging. This was not a significant problem with the miniexcavator, and with the SEE the problem was reduced by placing the lip of the loader bucket in a snow bank. Other expedient techniques should be considered to prevent motion during digging, including attaching the front of the machine to another object with a chain, or using more aggressive pads on the rear stabilizers.

Additional observations in unfrozen ground containing very large stones provided an interesting comparison between the ripper bucket and the standard bucket. Operation with the ripper bucket was smoother, with much less jarring and banging. Both the lip and ripper teeth engaged the rocks and tended to roll and lift them from the ground, in contrast to the conventional bucket where lip teeth slid and banged from rock to rock. The stones freed were usually picked up on the next pass.

\section{SUMMARY AND CONCLUSIONS}

Frozen ground was excavated at several sites with a mini-excavator and an Army Small Emplacement Excavator, both fitted with ripper buckets. There was a large variation in material types and frost conditions at the sites. Digging was accomplished under conditions that would have been very difficult to impossible with small machines fitted with conventional buckets. With the ripper bucket, the mini-excavator was capable of slowly cutting and ripping a dense, well-frozen sandy soil. These observations with a machine of marginal weight and power for this task helped to illustrate the cutting action of the bucket, the influence of cutter geometry on performance, and the potential of this device to improve the hard-ground digging capability of small machines. The larger SEE fitted with a ripper bucket was very effective in ripping a seasonal frost layer. The observations at Fort Drum suggest that a thin surface frost layer, 9 to 16 in. $(23$ to $40 \mathrm{~cm})$ thick, could be easily broken and partially removed, processing approximately 30 $\mathrm{yd}^{3}\left(23 \mathrm{~m}^{3}\right)$ of material in an hour. Used in this manner, the ripper bucket could rapidly prepare 
the ground for excavation by another SEE with a conventional bucket of larger capacity.

The ripper bucket observations made in Alaska with theSEE produced a large range of rates in frozen soils having similar properties. They varied from 2.5 to $9.5 \mathrm{yd}^{3} / \mathrm{hr}\left(1.9\right.$ to $\left.7.3 \mathrm{~m}^{3} / \mathrm{hr}\right)$, which could be attributed to operator experience and the degree of cutter wear. Even though these rates are not particularly high, it represented an improvement, since prior to this, troop units had to rely on jackhammers to excavate this material. The observations in Alaska were made in an area cleared of snow, with the surface containing coarse-grained material. This cold, well-bonded material should be more difficult to excavate than most natural seasonally frozen and permafrost soils in the region.

The observations in Alaska also included a digging exercise to illustrate the importance of sharp teeth. This was based on comparison of a set of worn flat-wedge teeth and newly sharpened teeth of the same design. The difference was very noticeable; there was a two- to three-fold increase in excavation rate with the sharp teeth. Availability of sharp teeth should not be a problem since an extra set can be carried on the machine. The teeth are easily replaced and can be sharpened on a bench grinder or with a hand-held disk grinder. The teeth are commonly available, and one of the types used was the same as those used on the SEE loader bucket.

The ripper bucket is made in three standard sizes -12 in. $(30 \mathrm{~cm}), 16$ in. $(40 \mathrm{~cm})$ and 24 in. $(60$ $\mathrm{cm}$ ) wide - and excavates a trench 1 to 2 in. (2.5 to $5.0 \mathrm{~cm}$ ) wider than the bucket. All of these buckets have five ripper teeth on the back. The 24-in. (60$\mathrm{cm})$ and 16-in. $(40-\mathrm{cm})$ buckets both have five teeth on the lip, while the 12 -in. $(30-\mathrm{cm})$ bucket has three. Tooth width is approximately $2 \mathrm{in}$. $(5 \mathrm{~cm})$. Based on ourdigging observations and experience with tools for working frozen ground, we selected the 16-in. bucket as most suited for use on machines of the size comparable to the Army SEE. This choice was based on an attempt to meet one of our design criteria for tools intended to work in a range of frozen earth materials. This criterion calls for teeth or cutters to excavate or cut the entire surface being advanced (Sellmann and Mellor 1986). This is important since some frozen soils behave in a ductile manner, and any uncut material can be left as a rib to slow the excavation process by rubbing on noncutting parts of the tool or machine. The 12-in. bucket best satisfied this criterion, since the five ripper teeth on the back of the bucket cut individual paths that come close to the total bucket width, with no uncut ribs. As bucket size increases, the uncut space between the teeth increases. The 16-in. bucket seems to be a good compromise since the uncut ribs should be narrow enough to fail during the digging process and permit a larger volume of material to be moved when material is easily excavated. The lip cutters also help to remove uncut material; however, this cannot be relied upon. When excessive vertical thrust is used, the lip cutters can prematurely roll up out of the work.

Performance was best when the machine could not move during aggressive digging in hard material. A way of preventing machine movement during an operation needs to be considered.

\section{LITERATURE CITED}

Blaisdell, G.L., E.J. Chamberlain and M. Mellor (1987) Evaluation of the cold regions aspect of mobility and hardening of the mobile test bed at Malmstrom Air Force Base. USA Cold Regions Research and Engineering Laboratory, Internal Report 1004.

Haynes, F.D. (1978) Effect of temperature on strength of snow-ice. USA Cold Regions Research and Engineering Laboratory, CRREL Report 78-27. Mellor, M. (1972) Strength and deformability of rocks at low temperatures. USA Cold Regions Research and Engineering Laboratory, Research Report 294.

Mellor, M. and P.V. Sellmann (1975) General considerations for drill system design. USA Cold Regions Research and Engineering Laboratory, Technical Report 264.

Monfore, G.E. and A.E. Lentz (1962) Physical properties of concrete at very low temperatures. Journal of the Portland Cement Association, p. 33-39.

Popp, D. (1991) Mini-excavators, Product: specifiers notebook. Highway and Heavy Construction, June Vol., p. 54-55.

Sellmann, P.V. (1972) Geology and properties of materials exposed in the USACRREL Permafrost Tunnel. USA Cold Regions Research and Engineering Laboratory, Special Report 177.

Sellmann, P.V. and M. Mellor (1986) Drill bits for frozen fine-grained soils. USA Cold Regions Research and Engineering Laboratory, Special Report 86-27.

Sellmann, P.V. (1989) Strength of soils and rocks at low temperatures. Cold Regions Science and Technology, Short Communications, 17: 189-190.

Smith, M. (1987) Spotlight, mini-excavators. Highway and Heavy Construction, Sept., p. 128-130. 
Public reporting burden for this collection of information is estimated to average 1 hour per response, including the time for reviewing instructions, searching existing data sources, gathering and maintaining the data needed, and completing and reviewing the collection of information. Send comments regarding this burden estimate or any other aspect of this collection of information. including suggestion for reducing this burden, to Washington Headquarters Services, Directorate for Information Operations and Reports, 1215 Jefferson Davis Highway, Suite 1204, Arlington, VA 22202-4302, and to the Office of Management and Budget, Paperwork Reduction Project (0704-0188), Washington, DC 20503.

\begin{tabular}{|l|l|l|l}
\hline 1. AGENCY USE ONLY (Leave blank) & $\begin{array}{l}\text { 2. REPORT DATE } \\
\text { June } 1992\end{array}$ & \begin{tabular}{l} 
3. REPORT TYPE AND DATES COVERED \\
\hline 4. TITLE AND SUBTITLE
\end{tabular} & 5. FUNDING NUMBERS \\
\hline
\end{tabular}

Digging Frozen Gound with a Ripper Bucket

PE:6.27.84A

6. AUTHORS

PR: 4A762784AT42

TA: CS

Paul V. Sellmann and Bruce E. Brockett

WU: 029

7. PERFORMING ORGANIZATION NAME(S) AND ADDRESS(ES)

U.S. Army Cold Regions Research and Engineering Laboratory

72. Lyme Road

Hanover, New Hampshire 03755-1290

8. PERFORMING ORGANIZATION

REPORT NUMBER

Special Report 92-15

9. SPONSORING/MONITORING AGENCY NAME(S) AND ADDRESS(ES)

Office of the Chief of Engineers

Washington, D.C. 20314-1000

11. SUPPLEMENTARY NOTES

12a. DISTRIBUTION/AVAILABILITY STATEMENT

12b. DISTRIBUTION CODE

Approved for public release; distribution is unlimited.

Available from NTIS, Springfield, Virginia 22161

13. ABSTRACT (Maximum 200 words)

To improve the digging capability of small excavators and backhoes in hard and frozen ground, a bucket of special design was selected from among a variety of attachments. This bucket cuts and rips the frozen ground, as lip teeth and a set of staggered teeth attached to the back of the bucket move through an arc during bucket rotation. Digging observations were made using a small mini-excavator and an Army tractor (SEE) with a rear-mounted backhoe. Frozen ground was excavated at several sites under impossible conditions for a conventional bucket. A large variation in excavation rates ( 3 to $30 \mathrm{yd}^{3} / \mathrm{hr}$ [2.3 to $\left.23 \mathrm{~m}^{3} / \mathrm{hr}\right]$ ) was observed, depending on material type, frost thickness, sharpness of the cutters and operator experience.

\begin{tabular}{|c|c|c|c|}
\hline \multicolumn{3}{|l|}{ 14. SUBJECT TERMS } & \\
\hline Backhoe ripper & Cold regions & Construction & Excavating frozen ground \\
\hline \multirow{2}{*}{$\begin{array}{l}\text { 17. SECURITY CLASSIFICATION } \\
\text { OF REPORT } \\
\text { UNCLASSIFIED }\end{array}$} & \multirow{2}{*}{\multicolumn{2}{|c|}{$\begin{array}{l}\text { 18. SECURITY CLASSIFICATION } \\
\text { OF THIS PAGE } \\
\text { UNCLASSIFIED }\end{array}$}} & $\begin{array}{l}\text { 19. SECURITY CLASSIFICATION } \\
\text { OF ABSTRACT }\end{array}$ \\
\hline & & & UNCLASSIFIED \\
\hline
\end{tabular}

15. NUMBER OF PAGES 15

16. PRICE CODE

20. LIMITATION OF ABSTRACT

UL

Standard Form 298 (Rev. 2-89) Prescribed by ANSI Std. Z39-18
$298-102$ 